NBER WORKING PAPER SERIES

\title{
MARIJUANA AND CRIME: \\ IS THERE A CONNECTION BEYOND PROHIBITION?
}

\author{
Rosalie Liccardo Pacula \\ Beau Kilmer \\ Working Paper 10046 \\ http://www.nber.org/papers/w10046
}

\author{
NATIONAL BUREAU OF ECONOMIC RESEARCH \\ 1050 Massachusetts Avenue \\ Cambridge, MA 02138 \\ October 2003
}

Research presented in this paper was supported by a grant from the National Institute on Drug Abuse (R01DA12724) to RAND. The opinions expressed in this paper are those of the authors and do not reflect the opinions of the author's institutions or funding agencies. Contact person: Rosalie Liccardo Pacula, RAND, 1700 Main St., P.O. Box 2138, Santa Monica, CA 90407-2138. Email: Pacula@rand.org. The views expressed herein are those of the authors and not necessarily those of the National Bureau of Economic Research.

C 2003 by Rosalie Liccardo Pacula and Beau Kilmer. All rights reserved. Short sections of text, not to exceed two paragraphs, may be quoted without explicit permission provided that full credit, including (C) notice, is given to the source. 
Marijuana and Crime: Is There a Connection Beyond Prohibition?

Rosalie Liccardo Pacula and Beau Kilmer

NBER Working Paper No. 10046

October 2003

JEL No. K14, K42, I18

\section{$\underline{\text { ABSTRACT }}$}

We examine the relationship between marijuana use and non-drug related crime using data on arrests from the Arrestee Drug Abuse Monitoring (ADAM) Program and Uniform Crime Reports. There is a positive association between self-reported use at the time of the offence and non-drug related violent, property and income-producing crime even after accounting for other substance use in the ADAM data. Reduced form equations using both data sets only provide evidence supporting a causal mechanism for property and income-producing crime. In the case of violent crime, we find a statistically significant association with arrests but not reported crime, suggesting that marijuana use may just influence the likelihood of getting caught committing these crimes.

Rosalie Liccardo Pacula

RAND

1700 Main Street

P.O. Box 2138

Santa Monica, CA 90407-2138

and NBER

pacula@rand.org

Beau Kilmer

Kennedy School of Government

Harvard University

John F. Kennedy Street

Cambridge, MA 02138

beau_kilmer@kgsphd.harvard.edu 


\section{Introduction}

An extensive literature exists examining the relationship between substance abuse and crime, the focus of which has typically centered on cocaine, heroin, and alcohol. Few studies specifically examine the relationship between marijuana and crime despite consistent findings that marijuana is the most commonly identified drug among arrestees. Reports from the United States, England, and Australia, for example, all show that approximately $60 \%$ of arrestees test positive for marijuana use and that marijuana is the drug whose metabolites are most frequently found in arrestees' urine (Taylor and Bennett, 1999; Makkai et al., 2000).

There are two good reasons why inferences should not be made about the relationship between marijuana and crime on the basis of urine tests of arrestees. First, very few arrestees who test positive for marijuana have only used marijuana. Most of those who test positive for marijuana also use other illicit drugs or alcohol (NIJ, 2000) ${ }^{1}$. The use of these other substances may be what motivated the criminal behavior rather than marijuana. Second, unlike other illegal substances, a positive urine sample for THC only indicates use in the past month; it does not indicate that marijuana was used immediately prior to the offence taking place. Hence, a positive urine test in the case of marijuana cannot be interpreted as evidence that the crime was committed under the influence of marijuana.

Despite its frequent use among arrestee populations, marijuana has generally been shown to inhibit aggressive behavior and violence in humans and thus it is believed not to be a major contributor to crime (Miczek et al., 1994; White and Gorman, 2000). However, in their review of the literature on the topic, the National Research Council concluded that the long-term use of marijuana may alter the nervous system in ways that do promote violence (National Research

\footnotetext{
${ }^{1}$ Data from the 1999 ADAM sample suggests this figure could exceed $70 \%$. Of the 16,684 arrestees who tested positive for marijuana, 7,748 (46.4\%) tested also tested positive for another illicit drug and another 4,436 (26.6\%) reported use of alcohol in the previous 72 hours.
} 
Council, 1993). Further, a consistent link between frequent cannabis use and violent crime and property damage has been identified among juveniles (Dembo et al., 1991; Salmelainen, 1995; Baker, 1998). Thus the issue of whether marijuana use causes crime, even if limited to a small segment of the population, remains in question.

The assumption that drugs and crime are causally related is a major reason for prohibiting the use of illicit drugs in many developed countries. If marijuana use is not the cause of crime, but merely defined as a crime, then one must consider all the criminal justice resources dedicated to arresting, processing, and adjudicating marijuana offenders as a cost of prohibition when weighing the cost and benefits of our current marijuana policy.

In this paper, we begin to investigate the causal association between marijuana use and crime. Using individual-level data from the Arrestee Drug Abuse Monitoring (ADAM) Program, we examine the relationship between marijuana use and the probability of getting arrested for a violent, property and income-producing and crime while controlling for concurrent use of alcohol and cocaine. Models consider the sensitivity of results when marijuana use is measured by a positive urine test, self-reported use in the past 3 days, and self-reported use at time of the offence. We find that marijuana use is positively associated with the likelihood of being arrested for a property and income-producing crime, with reduced form models supporting the conclusion that at least some of the association is causal in nature. This finding is further supported by additional analyses of the number of property and income-producing offence arrests measured in the Uniform Crime Reports (UCR). Models estimating the likelihood of being arrested for a violent crime using reduced form models are mixed, with no statistical association found in the ADAM sample and a positive association between marijuana use and violent crime arrests in the UCR sample. 
The rest of the paper is organized as follows. In the next section we provide some background on the hypothesized relationship between marijuana and crime and the findings to date. In section III we present the theoretical framework. In Section IV, we discuss the empirical model and the primary data sets used to estimate our models. In Section V we present our results and in Section VI we offer some discussion and conclusions.

\section{Background and Significance}

Surprisingly few studies have explicitly examined the relationship between cannabis use and crime. Those studies that have been done generally examine the association within the context of four alternative hypotheses based on Goldstein's (1985) tripartite framework, where the association between marijuana use and crime is explained by either psychopharmacological factors, economic-compulsive behavior, systemic violence or common factors.

The psychopharmacological model hypothesizes that drug users engage in violent and/or non-violent crime because of the acute psychoactive effects of the substance (Goldstein, 1985). There is very little support for this model in the case of marijuana, except for adolescents. Laboratory studies generally show that marijuana, unlike alcohol, temporarily inhibits aggression and violence (Mizcek et al, 1994; White and Gorman, 2000), raising doubt that any association identified in the data is causal in nature. Still, there is some evidence showing a correlation between chronic marijuana use and increased risk of violent behavior (White and Hansell, 1998; Kaplan and Damphousse, 1995).

Although cannabis use may temporarily inhibit aggression in the general population, it is possible that cannabis use increases aggression in some individuals. In controlled laboratory studies, for example, the relationship between alcohol use and aggression is influenced by 
subject characteristics, such as gender, aggressive tendencies and cognitive abilities, as well as experimental conditions, such as whether the subject was provoked (Bushman, 1997). Indeed, Bushman's (1990) meta-analysis found more aggression among marijuana smokers than placebo controls in laboratory experiments, although he notes that the placebo controls showed significantly less aggression than nondrug controls highlighting the importance of individual heterogeneity in general tendencies toward aggression. Nonetheless, it may be the case, as suggested by the US National Research Council (1993), that prolonged use of cannabis promotes violent or aggressive behavior because of changes in the nervous system.

There is far more convincing evidence of a link between frequent cannabis use and violent crime and nonviolent delinquency among juveniles (Salmelainen, 1995; Fergusson and Horwood, 1997; Baker, 1998). In a study of 10,441 secondary students in New South Wales, Australia, students who were frequent cannabis users were two times more likely to participate in assault and malicious damage of property than students who did not use cannabis. The relationship persisted after adjusting for differences in developmental characteristics, demographics and other substance use (Baker, 1998). ${ }^{2} \quad$ In a longitudinal analysis of a New Zealand birth cohort, Fergusson and Horwood (1997) considered four measures of delinquency in their analysis of the consequences of adolescent marijuana use: three or more violent offences, three or more property offences, arrested by police, and convicted of an offence in court. There was a dose-response relationship between each of these outcomes and frequency of marijuana use by age 16. This persisted after adjustment for covariates, suggesting that it was not wholly explained by the characteristics of adolescents who become regular marijuana users by age 16 . It

\footnotetext{
${ }^{2}$ The developmental factors controlled for in the model included parental supervision, family structure, school performance and truancy. The demographic factors accounted for were gender and Aboriginality. Other substance use indicators accounted for were infrequent and frequent use of alcohol and any use of opiates, stimulants, and steroids.
} 
also persisted after adjustment for drug use and criminal behaviour in the user's peer group, indicating that it was not explained by affiliating with delinquent and drug using peers.

Economic crime is that which is motivated by the need to generate income to fund one's own drug use (Goldstein, 1985). By comparison with other illicit drugs, marijuana consumption does not typically produce compulsive patterns of criminal behavior among users and it is not as expensive as other illicit drugs. However, studies suggest that there may be some economically motivated crime at least among youth. In studies of juvenile offenders in the United States and Australia, young offenders who reported frequent use of marijuana reported greater involvement in theft than non-users (Dembo, et al. 1991; Salmelainen 1995; Stevenson and Forsythe 1998). In addition, among juvenile offenders higher marijuana involvement was significantly correlated with higher rates of offending for specific property crimes (Salmelainen, 1995; Stevenson and Forsythe, 1998). The relationship was supported by Baker's (1998) study of secondary students from New South Wales, in which he found that frequent marijuana users were almost five times more likely to report participation in acquisitive property crime than non-users, even after controlling for individual characteristics, family background, and other substance use (Baker, 1998). ${ }^{3}$ What is perhaps most surprising about this study is the fact that frequent marijuana use was found to have a larger effect on participation in property crime than frequent alcohol use or any other illicit drug use.

Systemic violence is that which arises when violence is used to enforce contracts or to resolve "turf wars" in illicit drug markets. Such violence is motivated by the enormous profits that are generated by illicit drug sales and by the absence of legitimate law enforcement to resolve disputes. For a number of reasons it is doubtful that the experience of violence in heroin

\footnotetext{
${ }^{3}$ The author of the report defines acquisitive property crime as motor vehicle theft, breaking and entering, receiving or selling stolen goods, and shoplifting goods worth $\$ 20$ or more.
} 
and cocaine markets is applicable to marijuana markets. There is some evidence that violence has been generated by marijuana markets in a few places in the United States, but this has been extremely rare and very localized (Goldstein et al., 1989; ONDCP, 2001). For example, Goldstein et al (1989) found in their assessment of 414 drug-related homicides in New York City that only 6 were related to marijuana. Ethnographic work examining the drug market in New York City showed that although marijuana dealers dominated outdoor parks and streets during the early 1980s, the marijuana market was not associated with the violence seen in the crack market. In the United States today, the majority of marijuana sales are done in private so dealers do not see even see their competitors (ONDCP 2001, Taylor et al. 2001). Even the majority of arrestees report purchasing marijuana indoors (median was $71 \%$ ). The proportion of arrestees who made outdoor purchases of marijuana exceeded 50 percent in only 4 sites (Taylor et al., 2001).

Marijuana use and criminal behavior may also be associated because both behaviors are driven by a common cause, such as personal characteristics of individuals that motivate them to become involved in both behaviors (Hirschi and Gottfredson, 1988; Fagan, 1990; White 1990). Among the third factors that have been hypothesized to generate the association are: gang involvement (Fagan, 1990), peer effects (Gorman and White, 1995), general problem behavior during adolescence (Jessor and Jessor, 1977), and common environments or situational causes (Skogan, 1990; Fagan, 1993). There is evidence that substance use and delinquent behavior share many common causes or predictors. For example, many of the childhood risk factors for violence, such as hyperactivity, impulsiveness, risk taking, early school failure, peer rejection, and inability to delay gratification, have been identified as risk factors for teenage drug use and adult drug problems (Hawkins, Catalano, and Miller, 1992; Brook, Whiteman and Cohen, 1995). 
Although the common factor model is the model most commonly believed for marijuana, there is evidence supporting a causal mechanism and thus the question regarding a causal link even if limited to specific populations remains unanswered. In this paper we explore the relationship between marijuana use and criminal activity using data from two different data sources on crime, the Arrestee Drug Abuse Monitoring program (ADAM) and Uniform Crime Reports (UCR). Reduced form models are used to test the appropriateness of conclusions regarding the association between an individual's marijuana use and the likelihood of getting arrested for a violent, property, and income-producing crime.

\section{The Theoretical Framework}

Following the theoretical work of Ehrlich (1973), we assume that criminals are riskneutral expected utility maximizers and make decisions about whether to commit specific crimes based on whether the expected reward (benefit) is greater than the expected cost. The use of mind-altering substances, including marijuana, may influence one's perceptions of the expected payoff or expected cost of engaging in specific crimes or it may reduce one's natural inhibitions for engaging in criminal activity. The direct mechanism through which marijuana and other substances influences the individual's decision to commit an offense is not of immediate interest in this paper because the data are not sufficient to empirically test alternative causal mechanisms. We therefore focus on a reduced-form equation of the number of offences that individual $i$ living in jurisdiction $j$ chooses to become involved in at time $t\left(O_{i j t}\right)$, which can be specified as follows:

$$
O_{i j t}=O\left(E_{j t}, Y_{i t}, Z_{j t}, A_{i t}, M J_{i t}, O D_{i t}\right) .
$$

Here $E_{j t}$ is a vector of variables representing the enforcement risk (expected cost) of committing those offences in jurisdiction $j$ at time $t, Y_{i t}$ represents a vector of individual-level variables 
influencing the marginal benefit of committing the offence at time $t$, and $Z_{j t}$ represents other community economic factors that may influence either the marginal benefit or marginal cost of committing an offence in jurisdiction $j$ at time $t$. The variables $A_{i t}, M_{i t}$, and $O D_{i t}$, represent the amount of alcohol, marijuana and other drugs, respectively, consumed by individual $i$ during time $t$. Reduced form demand functions for each of these substances are derived from constrained maximization of the individual's expected utility function, and can be represented as follows:

(2) $A_{i t}=A\left(P_{A j t}, P_{M j t}, P_{O D j}, Y_{i t}\right)$

(3) $M J_{i t}=M J\left(P_{A j t}, P_{M j}, P_{O D j}, Y_{i t}\right)$

(4) $O D_{i t}=O D\left(P_{A j}, P_{M j}, P_{O D j}, Y_{i t}\right)$

where $P_{A}, P_{M}$, and $P_{O D}$ represent the price of alcohol, marijuana and other illicit drugs, respectively. Substituting equations (2) - (4) into equation (1) yields the following reduced-form equation:

(5) $O_{i j t}=O\left(E_{j t}, Y_{i t}, Z_{j t}, P_{A j}, P_{M j}, P_{O D j}\right)$.

If marijuana use does influence one's willingness to engage in crime, either by reducing one's natural inhibitions or by changing one's perceptions of the expected costs or benefits, then we would expect that an increase in the price of marijuana, which reduces the consumption of marijuana, would be negatively associated with the number of offences committed, or $\partial O_{i j t} / \partial P_{M j t}<0 .^{4}$ It is quite plausible in light of physiological properties of marijuana, however, that marijuana use only influences one's willingness to engage in certain types of crimes. Thus, in our empirical specification of the model, we separately examine the relationship between this substance and violent, property and income-producing crimes.

\footnotetext{
${ }^{4}$ As the literature review above shows, there is basically no evidence that marijuana markets themselves generate violence or crime, unlike the market for cocaine. Hence, we are implicitly assuming here that higher marijuana prices do not have a direct association with criminal behavior due to the need to protect territory or market share.
} 


\section{The Data and Empirical Models}

Two different data sets are used to explore the relationship between marijuana use and crime. The first source of data is the Arrestee Drug Abuse Monitoring (ADAM) Program (formerly Drug Use Forecasting System). Since 1987, the U.S. Department of Justice has interviewed arrestees in urban booking facilities about their drug use patterns as well as tested them for drug use. The purpose of the study is to provide local law enforcement and other local officials with reliable estimates of the prevalence of drug abuse and related problems in the population of arrestees in their jurisdiction. Sites were originally selected through applications from those jurisdictions interested in participating, but the number of sites increased substantially during the 1990s from 23 in 1996 to 35 in 1998 (See Appendix for complete list of sites).

Prior to 1998 the data generally reflect convenience samples, as they were collected from recent arrestees in the largest booking facility in the county. Since 1998, the sampling methodology has been modified so that the sampling frame now represents all arrestees within a county, not just those booked at the central booking facility. Data collection takes place four times a year (once each calendar quarter) at each site. Arrestees are approached within 48 hours of their arrest and asked to participate in the study. Although participation in ADAM is strictly voluntary, response rates hover around 80 to 90 percent (U.S. Department of Justice, 2000).

Although the data are non-representative of the overall arrestee population, they are the only data source where information on the offender's substance use near the time of the arrest is available. Self-reported use of various legal and illicit substances in the past year, past month and past 72 hours are obtained and validated through analysis of urine specimen. The urinanalyses can identify any of ten substances (including the NIDA-5: cocaine, opiates, marijuana, methamphetamine and PCP), but the results should be interpreted with caution since 
some drugs are detectable in the body for up to a month after consumption. Between 1995 and 1999, the survey also included questions pertaining to whether the offender was "under the influence" of specific drugs at the time of the offence. Given that marijuana is one of the drugs that remains detectable in the body for longer periods of time, knowledge of use of marijuana at the time of the offence is extremely important for validating a causal connection. Hence, we use information from the 1996 through 1999 ADAM data for our current analysis. Data from 1995 were not included because of a change in the method for evaluating a positive urine test during that year that resulted in an increase in the number of marijuana detections (NIJ, 1999).

ADAM reports up to three charges for each arrestee and classifies these into more than fifty offenses, ranging from murder to unlicensed vending. We aggregate the most serious offence into three broad categories: violent crime, property crime, and income producing crime. ${ }^{5}$ Violent crime includes murder, forcible rape, robbery and aggravated assault. Property crimes include burglary, larceny-theft, motor vehicle theft and arson. Income-producing crimes are defined as robbery, burglary, motor vehicle theft, forgery, embezzlement, stolen goods, and prostitution. For each type of crime in the ADAM data, we estimate the following regression model:

(6) $\operatorname{Pr}\left(O_{\text {cijt }}=1\right)=$

$$
\Phi\left(\alpha_{0}+\alpha_{1} P_{A j t}+\alpha_{2} P_{M j t}+\alpha_{3} P_{O D j t},+\alpha_{4} E_{j t}+\alpha_{5} Y_{i t}+\alpha_{6} Z_{j t}+\alpha_{7} W_{j}+\alpha_{8} Y e a r+\varepsilon_{i t}\right) .
$$

where $\mathrm{c}=$ violent crime, property crime and income producing crime, $\Phi$ is the cumulative distribution function of the univariate normal distribution, $W_{j}$ is a series of dummy variable for each ADAM site that pick up time invariant unobservable factors that are unique to each

\footnotetext{
${ }^{5}$ We group people by their most serious arrest charge for two main reasons. First, most arrestees are only charged with one offense. Second, the crime data from the FBI only report the arrest for the most serious charge (the hierarchy rule) and since this analysis utilizes both of these data sets it is useful to make them as consistent as possible.
} 
location, $\varepsilon_{i t}$ is an individual random error term which is assumed to be normally distributed, and the other variables are as specified previously. ${ }^{6}$ Our measure of local enforcement $\left(E_{j t}\right)$ is the number of full time sworn officers per capita, which was obtained from estimates reported in the Justice Expenditure and Employment Abstracts. These data are extracted from the Census Bureau's Annual Government Finance Survey and Annual Survey of Public Employment and includes the same jurisdictions covered by ADAM sites. ${ }^{7}$

Individual-level characteristics $\left(Y_{i t}\right)$ that are collected in the ADAM survey include age, gender, race, ethnicity, marital status, educational attainment, and income. In the case of income, two separate questions are included about legal and illegal income earned in the previous month. ${ }^{8}$ Other community factors $\left(Z_{j t}\right)$ also controlled for in these models include real per capita income and the local unemployment rate, obtained from the Census Bureau and Bureau of Labor Statistics, respectively.

Information on the monetary price of marijuana comes from various publications of the Illegal Drug Price/Purity Report, (IDPPR) published by the DEA Office of Intelligence or Intelligence Division of the U.S. Department of Justice. Although other sources of marijuana price data are available, the IDPPR published data represents the only source we are aware of in which it is possible to distinguish high and low quality marijuana consistently over time for the same locations. The IDPPR report the minimum and maximum retail (ounce) and wholesale (pound) price of commercial-grade and sinsemilla marijuana in 19 cities located in 16 states. These 19 cities represent main branch offices for the DEA. The price and quality information

\footnotetext{
${ }^{6}$ Year dummy variables were also explored but the dummies indicated a linear trend. Hence the linear trend was employed in all of the models.

${ }^{7}$ We also considered a measure of the relative crime per officers by constructing a measure of the total crime per number of full-time sworn officers. Results are qualitatively similar to those presented here.

${ }^{8}$ Individuals with missing information for either of these income measures, approximately $20 \%$ of our ADAM sample, were dropped from the current analysis.
} 
are obtained for purchases made by undercover police officers and DEA agents that are sent to a laboratory for analysis. For the purposes of this analysis, we focus on the quarterly prices for commercial marijuana sold at the retail level. Predicted quarterly prices are obtained using data from 1982 through 2001 to predict the natural logarithm of real price using indicators for the location of the DEA field office, year, interaction terms of the DEA field office and the year of purchase, and year squared. ${ }^{9}$ We match the predicted price to the ADAM data set based on quarter and to the UCR data based on year. Each ADAM site is assigned the predicted price of the closest within-state branch office that reported to one of the 19 main field offices.

Cocaine and alcohol prices are included to ensure that the estimated marijuana price effects do not reflect indirect effects through alcohol and cocaine consumption. Similar to previous studies, we use information about the price of cocaine from the DEA's STRIDE data. STRIDE contains records on acquisitions of cocaine (and other illicit drugs) made by undercover agents and informants of the DEA. For each cocaine acquisition, information is recorded about the type of cocaine (e.g. cocaine base (crack), cocaine hydrochloride (powder cocaine), and others), the quantity acquired, its purity (in percent), the cost (if the cocaine was purchase rather than seized), along with the DEA field office responsible for the acquisition and the date that it took place. In addition to cost differences arising from the form of cocaine, the cost of purchases may vary due to the weight and/or purity of the purchase. One method to account for differences in the weight purchased is to divide the (CPI deflated) cost of purchase by its weight to obtain a price per gram. However, this method ignores the quantity discounting evident in these data as well as differences due to actual purity. To overcome these issues, we follow the economics literature and form a predicted price of a pure gram of cocaine for each year and

\footnotetext{
${ }^{9}$ It is necessary to use predicted prices instead of actual prices because of missing data for particular cities and quarters.
} 
city. ${ }^{10}$ City-specific predicted quarterly and annual prices for one pure gram of cocaine were matched to the ADAM site on the basis of the closest city for which we had price data.

Information on the monetary cost of alcohol is represented by the CPI deflated sum of federal and state taxes on a twelve-ounce can of beer. These data are published annually in the Beer Institute's Brewers' Almanac. Information on state and local taxes is used for these analyses instead of city-level alcohol prices because city-specific prices are not consistently available through ACCRA for the ADAM locations in our sample. However, supplemental regressions using this alternative measure for alcohol price resulted in similar findings.

The ADAM data obviously represent a selective population in that we only observe individuals in these data if they committed an offence, were caught, and were sent to a booking facility that participates in the ADAM survey. Probabilistic samples were not drawn from most jurisdictions until 1998. Hence, there are numerous reasons to be concerned about the generalizability of findings obtained from these data. Therefore, we also examine reduced form models using data from the Federal Bureau of Investigation's Uniform Crime Reports (UCR) to test the robustness of our findings. The UCR system collects information on the number of crimes reported to the police in specific crime categories each year for every city in the country. Arrests are also reported for each jurisdiction by criminal offence. While the shortcomings of these data are well documented (e.g. O’Brien, 1985), they remain the only source of geographically disaggregated crime and arrest data in the United States.

\footnotetext{
${ }^{10}$ The model used to predict price is based on regressing the log of the real cost of purchase on the log of the weight of the purchase, the log of the purity of the purchase, indicators for the city of purchase, interactions between the city and year of purchase, the square of the year of purchase, and a set of indicators for the quarter of purchase. In order to address the issue of uncertainty of purity at the time of purchase, we replace actual purity with the predicted purity based on a model containing the regressors included in the model for the predicted price (except the year squared term and quarter dummies). The effect of (the log of) purity is identified in the cost model by constraining its coefficient to be equal to the coefficient on the (log of) weight of the purchase. We then predict the log of the price of a pure gram of cocaine for each city and year, and exponentiate this quantity to get the real price of a gram of cocaine. City-specific prices were estimated for those cities where at least 40 observations were observed over the period 1985-2000 to reduce the noise in the series.
} 
Because we are primarily concerned about ADAM's reliance on convenience sampling during the 1996-1999 time period, we restrict our UCR data to reflect the same 35 counties included in our ADAM sample. Further, we restrict the UCR time period to 1994 through 2000 so that it overlaps with our ADAM sample; thus we can reduce the number of plausible explanations for differences in results that might emerge across these two data sets. ${ }^{11}$

Publicly available data from the UCR provide information on crime and arrest rates, but no information is available on individual characteristics or whether crimes were committed under the influence of alcohol or illicit drugs. At best we can infer an association between crime and marijuana use from the UCR by using a reduced form model to determine if decreases in marijuana prices are associated with increases in particular types of crime. Using data from ADAM, we are able to confirm that use of marijuana among the arrestee population is price responsive (see Table A1 in the Appendix). ${ }^{12}$ Preliminary examination and statistical testing of the UCR data suggests that the appropriate empirical specification of equation (5) using these data varied by type of offence. ${ }^{13}$ In the case of violent crimes, we model the data using a general linear model with log-link function and nonconstant variance, or:

(7) $\mathrm{E}\left[(\text { violent crime arrests } / 10,000 \text { population })_{\mathrm{j} t}\right]=$

$$
\exp \left(\beta_{0}+\beta_{1} P_{A j t}+\beta_{2} P_{M j t}+\beta_{3} P_{O D j t}+\beta_{4} E_{j t}+\beta_{5} Z_{j t}+\beta_{6} W_{j}+\beta_{7} \text { Year }_{t}+v_{j t}\right)
$$

(8) $\mathrm{V}\left[(\text { violent crime arrests } / 10,000 \text { population })_{\mathrm{jt}}\right]=$ $\mathrm{E}^{2}\left[(\text { violent crime arrests/10,000 population })_{\mathrm{jt}}\right]$.

\footnotetext{
${ }^{11}$ It was necessary to expand the time horizon in the UCR data because our unit of observation in the UCR is a county-year. Thus a sample from 1996-1999 would have little statistical power. We chose the years 1994-2000 because trends in crime rates in these locations during that time period were consistent with what occurred during 1996-1999.

${ }^{12}$ The probability of using marijuana, as measured by all three indicators of use in our ADAM sample, is negatively associated with changes in price.

${ }^{13}$ The specific functional form was determined by empirically testing alternative functional forms suggested by boxcox transformations. The variance structure was determined through a modified Park Test (Deb, Manning, and Norton, 2003).
} 
In the case of property and income-producing crimes, we model these outcomes using general linear models with log-link functions and constant coefficient of variation, or:

(9) $\mathbf{E}\left[(\text { property crime arrests/10,000 population })_{\mathrm{jt}}\right]=$

$$
\exp \left(\delta_{0}+\delta_{1} P_{A j t}+\delta_{2} P_{M j t}+\delta_{3} P_{O D j t}+\delta_{4} E_{j t}+\delta_{5} Z_{j t}+\delta_{6} W_{j}+\delta_{7} \text { Year }_{t}+\mu_{j t}\right)
$$

(10) $\mathbf{V}\left[(\text { property crime arrests } / 10,000 \text { population })_{\mathrm{jt}}\right]=1$.

Because individual-level demographic information is not available in the public use UCR data we exclude $Y_{i t}$ from the equations above. County-level demographics, income and unemployment rates are included as components of the $Z_{j t}$ matrix, however. In addition, we account for county-level income and unemployment rates, obtained from the Bureau of Economic Analysis and Bureau of Labor Statistics, respectively. ${ }^{14}$

In our UCR analyses, we include an additional measure of local enforcement $\left(E_{j t}\right)$ so that we can account for the prominence of drug crime and drug enforcement activity in the area. In addition to a measure of the local crime per number of officers, we construct the ratio of local drug arrests to total reported crime from UCR data. Both our measures of enforcement are likely to be endogeneous in the UCR analyses. However, we are unable to identify variables that allow us to uniquely identify variation in law enforcement independent of arrests. Thus, to test the sensitivity of our main marijuana findings to the inclusion of these endogenous variables, we run two sets of models for each outcome. One set of models excludes these enforcement measures and one set includes them.

Descriptive statistics for the ADAM and UCR samples employed for all regression analyses are included in Table 1. Looking only at violent, property, and income-producing

\footnotetext{
${ }^{14}$ Unemployment figures were not available for the Anchorage FIPS so unemployment data for the Anchorage MSA are substituted (http://www.economagic.com/em-cgi/data.exe/blsla/lausm03800003).
} 
crimes, there is a larger share of income-producing crimes in the ADAM sample than in the UCR. And for both samples, violent crimes are the least common of the three categories. The predicted prices for cocaine and marijuana, on average, are slightly higher in the UCR sample, in part because the UCR data include data on all 35 locations going back to 1994. The ADAM data only have information for 23 of the 35 cities until 1998. The difference in county characteristics between the two samples therefore, can partially be explained by the inclusion of all cities for more years in the UCR and the fact that the ADAM sample draws a different number of observations from each jurisdiction. To adjust for the unequal weight attributed to various jurisdictions within the ADAM sample, all models are run using a Huber/White correction of the standard errors using the "robust" option in STATA 7.0.

\section{Results}

Table 2 provides a preliminary look at the association between marijuana use and specific types of crime for the full ADAM sample. When individuals charged with a drug offence are included in the sample, then marijuana users - identified through urine tests or self-reported use - are generally found to be less likely to be charged of a violent, property or incomeproducing crime than non-users. The notable exception are those individuals who reported use in the past three days who are statistically more likely to be arrested for property and income producing crime, but the finding of a positive association contradicts the result of a negative association for those self-reporting that they were under the influence at the time of the arrest.

Individuals who report being under the influence of alcohol at the time of the offence are more likely to be charged with a violent crime and less likely to be charged with a property or income-producing crime. Not surprisingly, the data show that marijuana users, regardless of 
how it is measured, are statistically more likely to be charged with a drug crime. Those under the influence of alcohol, however, are less likely to be charged of a drug-involved crime.

Given that we are only looking at those arrested, it is not surprising that marijuana users are more likely to be charged with a drug-related crime and less likely to be charged with other crimes simply because many marijuana users are picked up on drug charges. Once we take individuals arrested on drug charges out of the sample, however, we should not expect to see any sort of systematic relationship between marijuana use and specific arrest charges unless there is some sort of association (spurious or real) between marijuana use and these specific offences.

When we remove those arrested on drug charges from the sample, we see some interesting changes. In the case of violent crime, we find that those who report use of marijuana in the past three days or being under the influence at the time of the crime are no longer less likely to be charged with a violent crime than non-marijuana users. In fact, those with a positive urine test for marijuana are statistically more likely to be charged with a violent crime than those testing negative. Given that marijuana can be identified in urine for up to 30 days past the time of consumption, this suggests that individuals who engage in violent crimes are also likely to engage in marijuana use but the marijuana use is not necessarily related to their decision to engage in crime.

In the case of property and income-producing crime we find a more consistent story across different measures of marijuana use. Here we see that marijuana users, regardless of how it is measured, are more likely to be arrested for property and income-producing crime. Interestingly, this is the opposite of what we find for those who report being under the influence of alcohol. Those who report being under the influence of alcohol at the time of the offence are less likely to be in either property or income producing crimes than non-alcohol users. 
None of the previous findings control for observable factors that may be driving these associations. In Table 3 we present the marginal effects from a probit specification of the likelihood of being charged with a violent crime controlling for individual demographics, sources of income, county demographics, unemployment rates, and county law enforcement. ${ }^{15}$ Given the previous table demonstrated differences in findings based on the measure of marijuana that was employed, we decide to estimate each of the models using the three different measures of marijuana use as well as the price of marijuana so we could have a better understanding of how to interpret results from the models including price. Results from the first two models (M1 and M2) suggest that marijuana users are less likely to be charged with a violent arrest than nonusers. However, this finding does not hold in model 3 (M3), where use is measured at the time of the offence suggesting that the association identified in the first two models may not be causal in nature. Indeed, our reduced form specification of the model (M4) shows a positive but statistically insignificant relationship between marijuana price and the probability of a violent crime offence, reinforcing the conclusion that marijuana use is not causally related to violent criminal behavior.

Neither the beer tax nor the price of cocaine is statistically significant in these models, contrary to findings from previous studies (DeSimone, 2001; Lott and Mustard, 1997; Cook and Moore, 1993). Although this might appear to be somewhat surprising, it is easily explained by the limited longitudinal variation in these variables during the time period being evaluated and the inclusion of county fixed effects. Cross-sectional variation in the beer tax is captured by county-specific dummies that are included in the regression; the only independent variation that can be identified from the beer tax is the within state variation in real taxes over time. During

\footnotetext{
${ }^{15}$ Note that all individuals arrested on drug charges are removed from the sample used in this and all subsequent analyses.
} 
the time period being evaluated (1996 through 1999) there is minimal temporal variation in the real beer tax in the 26 states represented by the ADAM sites. ${ }^{16}$ A similar problem exists for cocaine, in that city and time dummy variables explain nearly $95 \%$ of the variation in cocaine prices during the period being examined here. However, some independent temporal variation still exists because of differences in seasonal fluctuation in the quarterly price of cocaine that differs across sites. We are less concerned about this issue in the case of marijuana prices because our demand models (shown in Appendix A1) demonstrate a negative and statistically significant association between price and consumption, as theory would suggest, even though time and county fixed effects are included. We interpret this as evidence that sufficient temporal variation exists in our marijuana price measure.

Given there is so little variation in the beer tax across locations, we are concerned that models including the beer tax may suffer an omitted variable bias that may lead to improper conclusions with respect to the relationship between marijuana use and crime. We therefore reran the models replacing the beer tax with a measure of self-reported use of alcohol at the time of the offence. We find that when we use this alternative measure of alcohol use we get a positive and statistically significant association between alcohol use and violent crime, consistent with the literature (DeSimone, 2001; Cook and Moore, 1993). More importantly, however, the inclusion of this alternative measure of alcohol use does not significantly alter our previous findings with respect to marijuana use. Although the coefficients on the self-reported marijuana use measures get larger in absolute value and self-reported marijuana use at the time of the crime becomes statistically significant, the marijuana price measure remains statistically insignificant. This supports the conclusion that the positive association implied by indicators of self-reported marijuana use is not be due to a causal mechanism.

\footnotetext{
${ }^{16}$ Alternative models were estimated using beer prices from ACCRA but this did not improve the results.
} 
In Table 4 we present findings from similar models of the probability of getting arrested for a property crime. Here our different measures of marijuana use generate some conflicting findings. When marijuana use is measured in terms of a positive urine sample (indicating use at some point in the previous thirty days), we find no statistical association between marijuana use and the likelihood of getting arrested for a property crime. If we instead use a more proximal measure of use (M2 and M3), we find that marijuana use is positively associated with the probability of getting arrested for a property crime although the finding with respect to use at the time of offence is only statistically significant at the $10 \%$ level. This positive association between marijuana use and property crime is confirmed in the reduced form version of the model (M4), where marijuana prices are found to have a negative and statistically significant association with the probability of arrest for a property crime, suggesting the association may be causal in nature. The positive association between recent marijuana use and property crime is invariant to the inclusion of self-reported alcohol use at the time of the offence (Models M6 through M8).

Contrary to what is found by DeSimone (2001), these models suggest that there is a negative association between powder cocaine use and property crime as higher powder cocaine prices (associated with lower cocaine use) are positively associated with property crime. The finding is fairly robust to variation in the measure of marijuana use and alcohol use. There are at least two plausible explanations for the difference in findings across studies. First, as was already stated, our model has limited variation in the price of cocaine because of our relatively short time period being evaluated and the inclusion of county-fixed effects. Thus, findings obtained from this relatively short panel may not be robust if evaluated over longer periods. Second, our method for predicting the price of cocaine differs substantially from that employed 
by DeSimone (2001).${ }^{17}$ For example, we do not include measures of crime and drug arrests when predicting cocaine prices and we exclude crack observations from our price regression so that our price series only reflects changes in the price of powder cocaine. ${ }^{18}$ Thus, we are cautious not to place too much importance on this finding.

In Table 5 we present results from models estimating the probability of being arrested for an income-producing crime. The results presented in these models again suggest that marijuana use is causally linked to crime as self-reported measures of marijuana use near the time of the arrest (Models M2 and M3) are positively and significantly associated with property crime and the price of marijuana is inversely related to income-producing crime at conventional levels of significance. The fact that the results from models M2 through M4 are substantially different than those implied by model M1, which relies on urinalysis for identification of use, suggests that we should be cautious drawing conclusions from associations identified off this measure of use.

As was the case in Table 4, we again see in Table 5 a positive association between cocaine prices and income-producing crime, but the same interpretation applies. An intriguing puzzle is presented in Table 5 by the different implied relationship between alcohol and incomeproducing crimes based on our two different measures of alcohol use. When the beer tax is used to capture the influence of alcohol consumption, we find that higher beer taxes, indicating less alcohol use, is associated with a lower likelihood of being arrested for an income-producing crime, consistent with results obtained elsewhere in the literature (DeSimone 2001, Gyimah-

\footnotetext{
${ }^{17}$ As indicated in the prior section, we use a much more restricted subset of the STRIDE data and do not include measures of arrest or crime in our estimation of the price of cocaine.

${ }^{18}$ There is a significant literature demonstrating an association between crack cocaine use and crime (Grogger and Willis, 2000; Inciardi, 1990; Fagan and Chin, 1990). It may be the case that by narrowing our focus to powder cocaine in the 1990s, we identify a different relationship between cocaine and crime. Future research will explore this hypothesis.
} 
Brempong, 2001). This contradicts findings obtained from models M5 through M8, however, where alcohol intoxication is shown to be negatively associated with getting arrested for incomeproducing crimes. The contradiction may simply be caused by an endogeneity bias that is generated from the inclusion of self-reported alcohol measures, but it is difficult to know for sure given the limited variability in the beer tax measure.

Overall the findings from the reduced form models would suggest that marijuana use is positively associated with property and income-producing crimes and that no causal association exists between marijuana use and violent crime. However, one must be careful drawing these conclusions based on analysis that only considers the likelihood of getting arrested for a specific criminal offence among a nonrandom sample of arrestees. Results from these models may not hold in the general population because this sample is not representative of the general arrestee population, the criminally involved population, or the general population.

To test the generalizability of these findings to the arrestee population, we estimated models of the number of arrests for violent, property and income producing crimes in the same geographic locations over a similar time period using county-level data from Uniform Crime Reports. Results from these models are presented in Table 6. In the case of the number of property crimes and income-producing crimes we obtain results that are consistent with those presented in Tables 4 and 5. Higher marijuana prices, indicative of lower marijuana use, are negatively and statistically associated with the number of property and income producing criminal arrests per capita, suggesting that marijuana use is positively associated with these measures of arrest. This finding is not sensitive to the inclusion of the endogenous enforcement measures (Column M2). 
We find a new result when the dependent variable is the number of violent arrests per capita. In the ADAM analysis (Table 2) we saw no statistical relationship between marijuana prices and the probability of an arrest for a violent offence. Here in Table 6 we see that marijuana prices are negatively and statistically associated with violent crime arrest rates, suggesting that marijuana use may be positively associated with violent crime as well. The result is robust to the inclusion of the endogenous enforcement measures.

It is important to consider the differences in the samples employed for these two analyses before interpreting these findings. The UCR and ADAM samples employed in Tables 2 and 6 differ in the following ways: the representativeness of the data samples; the inclusion of three extra years of data in the UCR analysis; the exclusion of individual demographics in the UCR analysis; and the presence of data for all thirty-five cities for all years in the UCR sample. ${ }^{19}$ We ran additional analyses exploring the influence of omitted demographics, the extra years, and the presence of cities in additional years and none of these factors led to a change in the statistical significance of the marijuana price variable, suggesting that the cause for the differential findings across the UCR and ADAM analysis is who is represented in the data.

Findings with respect to the beer tax and cocaine price also differ across the ADAM and UCR analysis. For example, beer taxes are shown in Table 6 to be positively associated with higher levels of all three arrests, which is inconsistent with the previous tables. Our supplemental analyses reveal that this finding is driven by the inclusion of all thirty-five counties in all years. When we restrict the UCR sample to just those counties that are in the sample ADAM sample in each year, we again see that there is no statistical association between the beer tax and any of the arrest rates. The sensitivity of the finding to the inclusion of additional counties in some years reinforces our concern regarding how to properly interpret any findings

\footnotetext{
${ }^{19}$ The ADAM sample grew from 23 cities in 1996 and 1997 to 35 cities in 1998 and 1999.
} 
from this variable. The findings with respect to the price of cocaine in Table 6 are much more consistent with the existing literature and are robust to changes in the county and years of data included. Thus, we believe that this difference in results pertaining to the cocaine price measure on crime rates identified across the different studies is largely being driven by a difference in the representativeness of the two alternative samples.

\section{Discussion}

Results from reduced form specifications of models of the number (UCR) and type (ADAM) of arrest suggest that marijuana use may actually be causally associated with specific types of crime, even for the general population of arrestees. Evidence from both sets of analyses suggest that higher marijuana use, as indicated by lower marijuana prices, is positively associated with property arrests and income-producing criminal arrests. There is also evidence from the UCR analysis that marijuana use might be positively associated with the number of violent arrests.

A significant limitation of the results so far is that we do not know the extent to which those arrested for crimes are behaviorally similar to those who commit crimes. It may be the case that substance use reduces an individual's ability to get away with a crime rather than influencing the likelihood of committing a crime. To consider this possibility, we re-ran our basic reduced form model using crime rates instead of arrest rates for the same locations in our ADAM sample. Although we recognize that crimes reported may not accurate reflect actual crimes committed, these are the only source of crime for all the locations in our ADAM sample. Results from these additional specifications are included in Table 7. Note that we are unable to estimate a model for the number of income-producing arrests per 10,000 residents because the data were not available at a disaggregated level. 
Results from our reduced form models predicting violent crime per 10,000 residents in the ADAM locations reinforce the original findings presented in Table 2 that marijuana use is not causally linked to violent criminal behavior. The marijuana price variable, although negative, is statistically insignificant at conventional levels and this null finding is invariant to the inclusion of general enforcement measures. The results from our models predicting property crime are more mixed, as the marijuana price variable is only negative and statistically significant when endogenous measures of enforcement are included in the model. Future work will need to carefully consider the proper treatment of these endogenous variables to fully understand the nature of the relationship between marijuana use and known property crimes.

The results from reduced form models tell a fairly consistent story across all of the tables. The positive association between marijuana use and arrests for property and income-producing crimes is not driven by a spurious correlation; these findings suggest a causal interpretation. These results are consistent with models using more proximate measures of use, including use of marijuana at the time of the offence. However, the proper interpretation of the result is still unclear. It may be the case that marijuana use causes individuals to participate in these crimes or it may be the case that marijuana use increases the likelihood that offenders get arrested for these crimes. Further investigation of this important distinction with other data sets will be necessary. The results pertaining to the relationship between marijuana use and violent crime are a bit more complex to interpret. Evidence from the ADAM sample of arrestees suggests that the positive association identified between marijuana use and violent crime is not causal in nature. This result is not confirmed in analyses using all known arrests from the ADAM cities, however. When UCR arrest data are employed a causal interpretation is supported. But the finding disappears again when crime is measured in terms of known offences as opposed to arrests, 
suggesting that the positive association identified in the UCR analysis may be driven by the fact that marijuana users who participate in crime are more likely to get arrested. Future work will need to consider the extent to which these current findings hold in a nationally representative sample of arrests and crime in order for us to clearly understand whether the criminal justice costs of marijuana prohibition are partially reimbursed through a reduction in crime. 


\section{References}

Baker, J. (1998). Juveniles in Crime - Part 1: Participation Rates and Risk Factors, Sydney: New South Wales Bureau of Crime Statistics and Research and New South Wales Crime Prevention Division.

Bushman, B.J. (1997). Effects of alcohol on human aggression: validity of proposed explanations. In Recent Developments in Alcoholism, Vol. 13, ed. M. Galanter, pp. 22743. New York: Plenum Press.

Bushman, B.J. (1990). Human aggression while under the influence of alcohol and other drugs: An integrative research review. Psychological Science, 2, 148-152.

Cook, PJ and M.J. Moore. (1993). "Violence reduction through restrictions on alcohol availability." Alcohol, Health and Research World, 17(2): 151-156.

Deb, P., Manning W., and E Norton. (2003). "Modeling Health Care Costs and Counts" Preconference workshop held before the International Health Economics Association 2003 Meeting (San Francisco, CA).

Dembo, R., Williams, L., Schmeidler, J., Wish, E.D., Getreu, A. and Berry, E. (1991). Juvenile crime and drug abuse: a prospective study of high risk youth. Journal of Addictive Disorders, 11 (2), 5-31.

DeSimone, J. (2001). The Effect of Cocaine Prices on Crime. Economic Inquiry. 39(4): 627-643.

Ehrlich, I. (1973). Participation in Illegitimate Activities: A Theoretical and Empirical Investigation. The Journal of Political Economy 81(3): 521-565.

Fagan, J. (1990). Intoxication and aggression. Drugs and crime. In Crime and Justice, A Review of Research, Vol. 13, ed. M. Tonry and J. Q. Wilson, pp. 241-320. Chicago: The University of Chicago Press.

Fagan, J.A. (1993). The political economy of drug dealing among urban gangs. In Drugs and Community, ed. R. Davis, A. Lurigio and D. P. Rosenbaum, pp. 19-54. Springfield, IL: Charles Thomas.

Fagan, J.A. and K.L. Chin. (1990). "Violence as Regulation and Social Control in the Distribution of Crack," National Institute on Drug Abuse Research Monograph Series 103: 8-43.

Fergusson, D. M., \& Horwood, L. J. (1997). Early onset cannabis use and psychosocial adjustment in young adults. Addiction, 92(3), 279-296.

Goldstein, P. (1985). The drugs/violence nexus: a tripartite conceptual framework. Journal of Drug Issues, 15 (Fall), 493-506.

Goldstein, P.J., Brownstein, H.H., Ryan, P.J. and Bellucci, P.A. (1989). Crack and homicide in New York City, 1988: a conceptually based event analysis. Contemporary Drug Problems, 16, 651-87.

Gorman, D.M. and White, H.R. (1995). You can choose your friends, but do they choose your crime? Implications of differential association theories for crime prevention policy. In Crime and Public Policy: Putting Theory to Work, ed. H. D. Barlow, pp. 131-55. Boulder, CO: Westview.

Grogger, J. and M. Willis. (2000). "The Emergence of Crack Cocaine and the Rise in Urban Crime Rates." The Review of Economics and Statistics, 82(4): 519-529. 
Gyimah-Brempong, K. (2001). "Alcohol Availability and Crime: Evidence from Census Tract Data" Southern Economic Journal 68(1): 2-21.

Hirschi, T. and Gottfredson, M. (1988). Towards a general theory of crime. In Explaining Criminal Behaviour: Interdisciplinary Approaches, ed. W. Buikhuisen and S. A. Mednick, pp. 8-26. Leiden; New York: E.J. Brill.

Inciardi, J.A. (1990). "The Crack-Violence Connection Within a Population of Hard-Core Adolescent Offenders," National Institute on Drug Abuse Research Monograph Series 103: 92-111.

Jessor, R. and Jessor, S.L. (1977). Problem Behavior and Psychosocial Development: A Longitudinal Study of Youth, New York: Academic Press.

Johnston, L.D., O'Malley, P.M. and Bachman, J.G. (2000). National Survey Results on Drug Use from the Monitoring the Future Study, 1975-1999 Volume II: College Students and Young Adults, Rockville, MD: National Institute on Drug Abuse.

Kaplan, Howard B. and Kelly R. and Damphousse 1995. Self-attitudes and antisocial personality as moderators of the drug use-violence relationship. In Drugs, crime and other deviant adaptions: Longitudinal studies, edited by Howard B. Kaplan. New York: Plenum Press.

Lott, JR and DB Musturd. (1997). Crime, Deterrence, and Right-to-Carry Concelaed Handguns." Journal of Legal Studies, 26: 1-68.

MacCoun, R. and Reuter, P. (2001). Drug War Heresies: Learning from Other Vices, Times and Places, Cambridge: Cambridge University Press.

Makkai, T., Fitzgerald, J. and Doak, P. (2000). Drug use among police detainees, Contemporary Issues in Crime and Justice, Vol. 49, Sydney: NSW Bureau of Crime Statistics and Research.

Markowitz, S. (2000). An Economic Analysis of Alcohol, Drugs and Crime in the National Criminal Victimization Survey, National Bureau of Economic Research Working Paper 7982. Cambridge, MA: National Bureau of Economic Research.

Miczek, K.A., DeBold, J.F., Haney, M., Tidey, J., Vivan, J. and Weerts, E.M. (1994). Alcohol, drugs of abuse, aggression, and violence. In Understanding and preventing violence, Vol. 3, ed. A. J. Reiss and J. A. Roth, pp. 377-570. Washington, DC: National Academy Press.

National Institute of Justice. (1999). 1998 Annual report on marijuana use among arrestees. http:/www.adam-nij.net/files/175658.pdf

National Institute of Justice. (2000). 1999 Annual report on marijuana use among arrestees.

National Research Council (1993). Understanding and Preventing Violence, Washington, DC: National Academy Press.

O’Brien, Robert. Crime and Victimization Data (Beverly Hills, CA: Sage). 1985.

Salmelainen, P. (1995). The correlates of offending frequency: a study of juvenile theft offenders in detention, Sydney: New South Wales Bureau of Crime Statistics and Research.

Skogan, W. (1990). Disorder and Decline: Crime and the Spiral Decay in American Neighbourhoods, New York: Free Press.

Stevenson, R. and Forsythe, L. (1998). The Stolen Goods Market in New South Wales: An Interview Study with Imprisoned Burglars, Sydney: NSW Bureau of Crime Statistics and Research.

Taylor, B. and Bennett, T. (1999). Comparing Drug Use Rates of Detained Arrestees in the United States and England, Washington, DC: U.S. Department of Justice. 
Taylor, B.G., Fitzgerald, N., Hunt, D., Reardon, J.A. and Brownstein, H.H. (2001). ADAM Preliminary 2000 Findings on Drug Use and Drug Markets - Adult Male Arrestees: National Institute of Justice.

United States Office of National Drug Control Policy (2001). Pulse Check: Trends in Drug Abuse. November 2001, Washington, DC: Office of National Drug Control Policy.

White, H.R. (1990). The drug use-delinquency connection in adolescence. In Drugs, Crime and the Criminal Justice System, ed. R. A. Weisheit, pp. 215-56. Cincinnati, OH: Anderson Publishing.

White, Helene Raskin and Stephen Hansell. 1998. Acute and long-term effects of drug use on aggression from adolescence into adulthood. Journal of Drug Issues. 28: 837-858.

White, H.R. and Gorman, D.M. (2000). Dynamics of the drug-crime relationship. In The Nature of Crime: Continuity and Change, ed. G. LaFree, pp. 151-218. Washington, DC: U.S. Department of Justice.

White, Helene Raskin and Stephen Hansell. 1998. Acute and long-term effects of drug use on aggression from adolescence into adulthood. Journal of Drug Issues. 28: 837-858. 


\begin{tabular}{|c|c|c|c|c|c|c|c|c|c|}
\hline & & & & & e 1 & & & & \\
\hline & & & Mea & ns of Pri & ary Data Sets & & & & \\
\hline ADAM & Analysis & & & & UC & CR Analys & & & \\
\hline $\mathbf{N}=$ & 101,960 & & & & & $N=188$ & & & \\
\hline Variable & Mean & Std. Dev & Min & Max & Variable & Mean & Std. Dev & Min & Max \\
\hline Positive Urine Test & 0.349 & 0.477 & 0 & 1 & Violent arrests per capita & 33.030 & 20.773 & 7.071 & 113.250 \\
\hline Use in past 3 days & 0.266 & 0.442 & 0 & 1 & Log(violent arrests per capita) & 3.327 & 0.576 & 1.956 & 4.730 \\
\hline Under the infl: MJ & 0.051 & 0.220 & 0 & 1 & Property arrests per capita & 94.870 & 29.607 & 27.546 & 188.901 \\
\hline Under the infl: Alc & 0.211 & 0.408 & 0 & 1 & Log(property arrests per capita) & 4.500 & 0.333 & 3.316 & 5.241 \\
\hline Arrested for violent crime & 0.183 & 0.387 & 0 & 1 & Income arrests per capita & 52.937 & 27.000 & 13.153 & 186.691 \\
\hline Arrested for property crime & 0.246 & 0.431 & 0 & 1 & Log(income arrests per capita) & 3.861 & 0.460 & 2.577 & 5.229 \\
\hline Arrested for income crime & 0.320 & 0.467 & 0 & 1 & & & & & \\
\hline Real predicted price of $\mathrm{MJ}$ & 55.21 & 18.940 & 20.37 & 101.02 & Real predicted price of MJ & 58.539 & 19.024 & 23.839 & 98.268 \\
\hline Real beer tax & 2.32 & 1.972 & 0.59 & 10.76 & Real beer tax & 2.462 & 1.863 & 0.577 & 11.454 \\
\hline Real predicted price of cocaine & 65.76 & 14.730 & 34.34 & 105.85 & Real predicted price of cocaine & 68.699 & 14.558 & 34.944 & 103.710 \\
\hline Male & 0.753 & 0.431 & 0 & 1 & Match dummy & 0.938 & 0.243 & 0 & 1 \\
\hline Black & 0.465 & 0.499 & 0 & 1 & & & & & \\
\hline Hispanic & 0.214 & 0.410 & 0 & 1 & $\%$ male & 0.484 & 0.012 & 0.463 & 0.514 \\
\hline Other race & 0.031 & 0.173 & 0 & 1 & $\%$ pop less than 18 & 0.257 & 0.032 & 0.180 & 0.366 \\
\hline Education $>=12$ & 0.420 & 0.494 & 0 & 1 & $\%$ pop 18-24 & 0.099 & 0.011 & 0.071 & 0.128 \\
\hline Age 18-24 & 0.264 & 0.441 & 0 & 1 & $\%$ white & 0.762 & 0.160 & 0.320 & 0.991 \\
\hline Age $25-34$ & 0.295 & 0.456 & 0 & 1 & $\%$ black & 0.182 & 0.170 & 0.002 & 0.649 \\
\hline Age $>34$ & 0.299 & 0.458 & 0 & 1 & $\%$ other & 0.056 & 0.046 & 0.007 & 0.228 \\
\hline Real income - illegal sources & 180.80 & 1185.47 & 0 & 63734 & $\%$ hispanic & 0.175 & 0.200 & 0.005 & 0.953 \\
\hline Real income - legal sources & 573.64 & 1423.63 & 0 & 63734 & unemployment rate & 4.911 & 1.932 & 1.900 & 15.400 \\
\hline Year & 1997.60 & 1.145 & 1996 & 1999 & Real per capita income (in $\$ 1000$ & 18.294 & 5.533 & 7.959 & 49.019 \\
\hline Unemployment rate & 4.700 & 1.580 & 1.9 & 9.2 & Log(county pop) & 13.852 & 0.826 & 12.000 & 16.049 \\
\hline FTE police per capita & 0.004 & 0.006 & 0.001 & 0.030 & Year & 1997 & 1.712 & 1994 & 1999 \\
\hline Real per capita income (in $\$ 1000$ ) & 19483 & 7213 & 8471 & 49019 & Index Crime & 94384.5 & 89798.9 & 9447 & 591795 \\
\hline$\%$ male & 0.484 & 0.012 & 0.463 & 0.513 & FTE sworn officers & 4178.9 & 7576.1 & 250 & 46158 \\
\hline$\%$ pop < 18 & 0.252 & 0.029 & 0.182 & 0.366 & total drug arrests/index crime & 0.117 & 0.068 & 0.020 & 0.430 \\
\hline$\%$ pop 18-24 & 0.098 & 0.011 & 0.074 & 0.128 & Index crime/ FTE sworn officers & 0.569 & 0.542 & 0.009 & 2.725 \\
\hline$\%$ black & 0.216 & 0.173 & 0.002 & 0.642 & & & & & \\
\hline$\%$ other & 0.060 & 0.050 & 0.007 & 0.228 & & & & & \\
\hline$\%$ hisp & 0.199 & 0.175 & 0.006 & 0.953 & & & & & \\
\hline & & & & & & & & & \\
\hline & & & & & & & & & \\
\hline
\end{tabular}




\begin{tabular}{|c|c|c|c|c|c|}
\hline & & Table 2 & & & \\
\hline & \multicolumn{3}{|c|}{ Descriptive Statistics } & & \\
\hline & \multicolumn{3}{|c|}{1996 - 1999 ADAM data } & & \\
\hline & & Full & & & P-value \\
\hline & \# of Obs & Sample & Non User & User & for diff $\sim=0$ \\
\hline \multicolumn{6}{|c|}{ PANEL A : Includes those charged of a drug offence } \\
\hline \multicolumn{6}{|l|}{ Violent Crime } \\
\hline MJ: Positive urine test & 137409 & 0.148 & 0.148 & 0.147 & 0.544 \\
\hline MJ: Use in past 3 days & 137091 & 0.148 & 0.152 & 0.138 & 0.000 \\
\hline MJ: under influence & 136496 & 0.148 & 0.149 & 0.130 & 0.000 \\
\hline ALC: under influence & 136497 & 0.148 & 0.142 & 0.171 & 0.000 \\
\hline \multicolumn{6}{|l|}{ Property Crime } \\
\hline MJ: Positive urine test & 137409 & 0.197 & 0.199 & 0.193 & 0.014 \\
\hline MJ: Use in past 3 days & 137091 & 0.197 & 0.195 & 0.201 & 0.019 \\
\hline MJ: under influence & 136496 & 0.196 & 0.197 & 0.184 & 0.003 \\
\hline ALC: under influence & 136497 & 0.196 & 0.210 & 0.143 & 0.000 \\
\hline \multicolumn{6}{|l|}{ Income Crime } \\
\hline MJ: Positive urine test & 137409 & 0.255 & 0.258 & 0.250 & 0.000 \\
\hline MJ: Use in past 3 days & 137091 & 0.255 & 0.252 & 0.264 & 0.000 \\
\hline MJ: under influence & 136496 & 0.255 & 0.256 & 0.244 & 0.021 \\
\hline ALC: under influence & 136497 & 0.255 & 0.273 & 0.186 & 0.000 \\
\hline \multicolumn{6}{|l|}{ Drug-Involved Crime } \\
\hline MJ: Positive urine test & 137409 & 0.187 & 0.164 & 0.227 & 0.000 \\
\hline MJ: Use in past 3 days & 137091 & 0.187 & 0.162 & 0.249 & 0.000 \\
\hline MJ: under influence & 136496 & 0.187 & 0.179 & 0.313 & 0.000 \\
\hline ALC: under influence & 136497 & 0.187 & 0.198 & 0.145 & 0.000 \\
\hline \multicolumn{6}{|c|}{ PANEL B: Excludes those charged with a drug offence } \\
\hline \multicolumn{6}{|l|}{ Violent Crime } \\
\hline MJ: Positive urine test & 111721 & 0.182 & 0.178 & 0.190 & 0.000 \\
\hline MJ: Use in past 3 days & 111459 & 0.182 & 0.181 & 0.183 & 0.382 \\
\hline MJ: under influence & 110969 & 0.182 & 0.181 & 0.189 & 0.156 \\
\hline ALC: under influence & 110970 & 0.182 & 0.177 & 0.200 & 0.000 \\
\hline \multicolumn{6}{|l|}{ Property Crime } \\
\hline MJ: Positive urine test & 111721 & 0.242 & 0.238 & 0.250 & 0.000 \\
\hline MJ: Use in past 3 days & 111459 & 0.242 & 0.233 & 0.267 & 0.000 \\
\hline MJ: under influence & 110969 & 0.242 & 0.240 & 0.268 & 0.000 \\
\hline ALC: under influence & 110970 & 0.242 & 0.262 & 0.167 & 0.000 \\
\hline \multicolumn{6}{|l|}{ Income Crime } \\
\hline MJ: Positive urine test & 111721 & 0.314 & 0.309 & 0.323 & 0.000 \\
\hline MJ: Use in past 3 days & 111459 & 0.314 & 0.300 & 0.352 & 0.000 \\
\hline MJ: under influence & 110969 & 0.314 & 0.311 & 0.356 & 0.000 \\
\hline ALC: under influence & 110970 & 0.314 & 0.340 & 0.218 & 0.000 \\
\hline
\end{tabular}




\begin{tabular}{|c|c|c|c|c|c|c|c|c|c|}
\hline & & & Table 3 & & & & & & \\
\hline \multicolumn{10}{|c|}{ Marginal Effects and Robust Standard Errors from Probit Estimation of } \\
\hline & \multicolumn{5}{|c|}{ Prob(Arrested for a Violent Crime) ${ }^{a}$} & & & & \\
\hline & \multicolumn{5}{|c|}{ ADAM 1996 - 1999, Non-drug offenders } & & & & \\
\hline & M1 & & M2 & & M3 & & M4 & & \\
\hline MJ: positive urine & -0.0054 & ** & & & & & & & \\
\hline & $(0.003)$ & & & & & & & & \\
\hline \multirow[t]{2}{*}{ MJ in past 3 days } & & & -0.0111 & *** & & & & & \\
\hline & & & $(0.003)$ & & & & & & \\
\hline MJ: under influence & & & & & -0.0084 & & & & \\
\hline & & & & & $(0.005)$ & & & & \\
\hline Real price of MJ & & & & & & & 0.0002 & & \\
\hline & & & & & & & $(0.001)$ & & \\
\hline Real beer tax & -0.0112 & & -0.0122 & & -0.0113 & & -0.0136 & & \\
\hline & $(0.041)$ & & $(0.041)$ & & $(0.041)$ & & $(0.042)$ & & \\
\hline \multirow[t]{2}{*}{ Real price of cocaine } & -0.0002 & & -0.0002 & & -0.0002 & & -0.0002 & & \\
\hline & $(0.001)$ & & $(0.001)$ & & $(0.001)$ & & $(0.001)$ & & \\
\hline \multirow{2}{*}{$\begin{array}{l}\text { County Fixed Effects } \\
\text { \# of Observations }\end{array}$} & Yes & & Yes & & Yes & & Yes & & \\
\hline & 101,960 & & 101,960 & & 101,960 & & 101,960 & & \\
\hline Pseudo-R2 & 0.051 & & 0.051 & & 0.051 & & 0.051 & & \\
\hline & M5 & & M6 & & M7 & & M8 & & \\
\hline MJ: positive urine & -0.0066 & $* *$ & & & & & & & \\
\hline & $(0.003)$ & & & & & & & & \\
\hline \multirow[t]{2}{*}{ MJ in past 3 days } & & & -0.0144 & $* * *$ & & & & & \\
\hline & & & $(0.003)$ & & & & & & \\
\hline MJ: under influence & & & & & -0.0191 & $\star \star \star *$ & & & \\
\hline & & & & & $(0.005)$ & & & & \\
\hline \multirow[t]{2}{*}{ Real price of MJ } & & & & & & & 0.0002 & & \\
\hline & & & & & & & $(0.001)$ & & \\
\hline \multirow[t]{2}{*}{ ALC: under influence } & 0.0493 & $* * *$ & 0.0503 & $* * *$ & 0.0506 & $* * *$ & 0.0490 & $* * *$ & \\
\hline & $(0.003)$ & & $(0.003)$ & & $(0.003)$ & & $(0.003)$ & & \\
\hline \multirow[t]{2}{*}{ Real price of cocaine } & -0.0002 & & -0.0001 & & -0.0002 & & -0.0001 & & \\
\hline & $(0.001)$ & & $(0.001)$ & & $(0.001)$ & & $(0.001)$ & & \\
\hline County Fixed Effects & Yes & & Yes & & Yes & & Yes & & \\
\hline \# of Observations & 101,960 & & 101,960 & & 101,960 & & 101,960 & & \\
\hline Pseudo-R2 & 0.053 & & 0.054 & & 0.053 & & 0.053 & & \\
\hline & & & & & & & & & \\
\hline \multirow{2}{*}{\multicolumn{10}{|c|}{$\begin{array}{l}{ }^{a} \text { Models include as additional regressors gender, ethnicity, race, education, age categories, legal } \\
\text { and illegal income, quarter dummies, time trend, county unemployment rate, the number of police }\end{array}$}} \\
\hline & & & & & & & & & \\
\hline \multicolumn{10}{|c|}{ demographics of the county. Statistical significance is designated as follows: ${ }^{* * *}$ indicates } \\
\hline significance at the $1 \%$ & (2-tailed te & st), * & indicates & signi & ficance at & the 5 & $\%$ level, ar & $d^{*}$ ir & ndicates \\
\hline significance at the $10^{\circ}$ & & & & & & & & & \\
\hline
\end{tabular}




\begin{tabular}{|c|c|c|c|c|c|c|c|c|c|}
\hline & & & Table 5 & & & & & & \\
\hline \multicolumn{8}{|c|}{ Marginal Effects and Robust Standard Errors from Probit Estimation of } & & \\
\hline & \multicolumn{6}{|c|}{ Prob(Arrested for an Income-Producing Crime) ${ }^{a}$} & \multirow[b]{3}{*}{ M4 } & & \\
\hline & \multicolumn{5}{|c|}{ ADAM 1996 - 1999, Non-drug offenders } & & & & \\
\hline & M1 & & M2 & & M3 & & & & \\
\hline MJ: positive urine & 0.0023 & & & & & & & & \\
\hline & $(0.003)$ & & & & & & & & \\
\hline \multirow[t]{2}{*}{ MJ in past 3 days } & & & 0.0361 & $* * *$ & & & & & \\
\hline & & & $(0.004)$ & & & & & & \\
\hline MJ: under influence & & & & & 0.0236 & $* * *$ & & & \\
\hline & & & & & $(0.007)$ & & & & \\
\hline Real price of MJ & & & & & & & -0.0047 & *** & \\
\hline & & & & & & & $(0.001)$ & & \\
\hline \multirow[t]{2}{*}{ Real beer tax } & -0.1007 & * & -0.0983 & * & -0.1018 & $* *$ & -0.0574 & & \\
\hline & $(0.052)$ & & $(0.052)$ & & $(0.052)$ & & $(0.054)$ & & \\
\hline Real price of cocaine & 0.0045 & $* * *$ & 0.0045 & $* * *$ & 0.0045 & $* * *$ & 0.0047 & $\star \star \star *$ & \\
\hline & $(0.001)$ & & $(0.001)$ & & $(0.001)$ & & $(0.001)$ & & \\
\hline \multirow{2}{*}{$\begin{array}{l}\text { County Fixed Effects } \\
\text { \# of Observations }\end{array}$} & Yes & & Yes & & Yes & & Yes & & \\
\hline & 101,960 & & 101,960 & & 101,960 & & 101,960 & & \\
\hline Pseudo-R2 & 0.049 & & 0.050 & & 0.049 & & 0.049 & & \\
\hline & M5 & & M6 & & M7 & & M8 & & \\
\hline MJ: positive urine & 0.0046 & & & & & & & & \\
\hline & $(0.003)$ & & & & & & & & \\
\hline MJ in past 3 days & & & 0.0432 & $* \star *$ & & & & & \\
\hline & & & $(0.004)$ & & & & & & \\
\hline MJ: under influence & & & & & 0.0479 & $* * *$ & & & \\
\hline & & & & & $(0.007)$ & & & & \\
\hline Real price of MJ & & & & & & & -0.0053 & $* * *$ & \\
\hline & & & & & & & $(0.001)$ & & \\
\hline ALC: under influence & -0.0961 & $* * *$ & -0.0993 & $* * *$ & -0.0992 & $* * *$ & -0.0960 & $* * *$ & \\
\hline & $(0.004)$ & & $(0.004)$ & & $(0.004)$ & & $(0.004)$ & & \\
\hline \multirow[t]{2}{*}{ Real price of cocaine } & 0.0052 & $* * *$ & 0.0051 & $* * *$ & 0.0052 & $* * *$ & 0.0051 & $* * *$ & \\
\hline & $(0.001)$ & & $(0.001)$ & & $(0.001)$ & & $(0.001)$ & & \\
\hline County Fixed Effects & Yes & & Yes & & Yes & & Yes & & \\
\hline \# of Observations & 101,960 & & 101,960 & & 101,960 & & 101,960 & & \\
\hline Pseudo-R2 & 0.054 & & 0.055 & & 0.054 & & 0.054 & & \\
\hline & & & & & & & & & \\
\hline \multirow{3}{*}{\multicolumn{10}{|c|}{$\begin{array}{l}\text { a Models include as additional regressors gender, ethnicity, race, education, age categories, legal } \\
\text { and illegal income, quarter dummies, time trend, county unemployment rate, the number of police } \\
\text { per capita, real county income, \% county population that male, black and other race, and age }\end{array}$}} \\
\hline & & & & & & & & & \\
\hline & & & & & & & & & \\
\hline \multicolumn{10}{|c|}{ demographics of the county. Statistical significance is designated as follows: ${ }^{* * *}$ indicates } \\
\hline significance at the $1 \%$ & evel (2-tailed te & t) $* *$ & indicates s & nific & nce at the & $=0 / 1+1$ & vel, and * & & \\
\hline significance at the $10^{\circ}$ & level. & & & & & & & & \\
\hline
\end{tabular}


Table 6

GLM Estimates of Log Arrest Rates from UCR: 1994 -1999

\begin{tabular}{|c|c|c|c|c|}
\hline & \multicolumn{2}{|l|}{ M1 } & \multicolumn{2}{|l|}{ M2 } \\
\hline & $\begin{array}{c}\text { OLS } \\
\text { Coefficient }\end{array}$ & $\begin{array}{l}\text { Robust } \\
\text { Std. Err }\end{array}$ & $\begin{array}{c}\text { OLS } \\
\text { Coefficient }\end{array}$ & $\begin{array}{l}\text { Robust } \\
\text { Std. Err }\end{array}$ \\
\hline & \multicolumn{4}{|c|}{ Log (\# of violent crime arrests/10K pop) } \\
\hline Real price of $\mathrm{MJ}$ & $-0.017^{* * *}$ & 0.006 & $-0.022^{* * *}$ & 0.004 \\
\hline Real price of Cocaine & 0.002 & 0.003 & -0.001 & 0.003 \\
\hline Real beer tax & $0.215^{* * *}$ & 0.079 & $0.256 * * *$ & 0.087 \\
\hline log(county pop) & $-1.853^{* * *}$ & 0.452 & -0.447 & 0.627 \\
\hline$\%$ of county pop $<18$ & $11.059 * * *$ & 3.809 & 4.536 & 4.182 \\
\hline$\%$ of county pop black & 1.390 & 5.636 & -0.318 & 4.289 \\
\hline$\%$ of county pop other race & $34.256 * * *$ & 10.077 & $42.310 * * *$ & 8.264 \\
\hline$\%$ of county pop Hispanic & -8.914 * & 5.122 & $-13.333^{* * *}$ & 3.971 \\
\hline Real per capita income & $-3.59 \mathrm{E}-05 * * *$ & 1.21E-05 & $-8.51 \mathrm{E}-05 * * *$ & 1.51E-05 \\
\hline Unemployment rate & 0.013 & 0.014 & 0.007 & 0.012 \\
\hline Year & $-0.037 *$ & 0.019 & $-0.059 * * *$ & 0.015 \\
\hline Crime per officer & & & $0.440^{* * *}$ & 0.128 \\
\hline Drug arrests/total crime & & & $3.342^{* * *}$ & 0.888 \\
\hline \multirow[t]{2}{*}{ Constant } & $97.940^{* * *}$ & 36.451 & $126.071^{* * *}$ & 29.710 \\
\hline & \multicolumn{4}{|c|}{ Log (\# of property crime arrests / $10 \mathrm{~K}$ pop) } \\
\hline Real price of MJ & $-0.010^{* *}$ & 0.005 & $-0.013^{* \star *}$ & 0.005 \\
\hline Real price of Cocaine & -0.002 & 0.002 & $-0.004^{* *}$ & 0.002 \\
\hline Real beer tax & $0.177^{* * *}$ & 0.066 & $0.151^{* *}$ & 0.066 \\
\hline $\log ($ county pop) & -0.482 & 0.336 & 0.023 & 0.398 \\
\hline$\%$ of county pop < 18 & $15.342 * * *$ & 3.704 & $15.407^{* * *}$ & 3.751 \\
\hline$\%$ of county pop black & 1.032 & 4.223 & 0.472 & 4.023 \\
\hline$\%$ of county pop other race & 8.091 & 8.343 & $16.737^{* *}$ & 8.068 \\
\hline ty pop Hispanic & -5.199 & 4.505 & $-8.291 *$ & 4.371 \\
\hline Real per capita income & $-1.18 \mathrm{E}-05$ & 1.35E-05 & $-3.36 \mathrm{E}-05 * * *$ & 1.19E-05 \\
\hline Unemployment rate & 0.013 & 0.009 & 0.007 & 0.009 \\
\hline Year & $-0.049 * * *$ & 0.015 & $-0.063^{* * *}$ & 0.017 \\
\hline Crime per officer & & & $0.341^{* * *}$ & 0.083 \\
\hline Drug arrests/total crime & & & 1.562 *** & 0.420 \\
\hline \multirow[t]{2}{*}{ Constant } & $106.099^{* * *}$ & 33.664 & $125.901 * * *$ & 32.365 \\
\hline & \multicolumn{4}{|c|}{ Log(\# of income arrests/ 10K pop) } \\
\hline Real price of MJ & $-0.011^{* *}$ & 0.005 & $-0.017^{* * *}$ & 0.004 \\
\hline Real price of Cocaine & -0.004 & 0.003 & $-0.005^{* *}$ & 0.003 \\
\hline Real beer tax & $0.154 *$ & 0.084 & $0.238^{* * *}$ & 0.072 \\
\hline $\log ($ county pop) & $-1.008 * * *$ & 0.378 & 0.303 & 0.490 \\
\hline$\%$ of county pop $<18$ & $20.707^{* * *}$ & 3.867 & $17.411^{* * *}$ & 3.946 \\
\hline$\%$ of county pop black & 7.775 & 4.904 & $6.447 *$ & 3.743 \\
\hline$\%$ of county pop other race & 13.805 & 9.064 & $19.349 * *$ & 8.662 \\
\hline$\%$ of county pop Hispanic & -3.963 & 4.033 & $-10.916^{* * *}$ & 3.708 \\
\hline Real per capita income & $-1.43 E-05$ & 1.45E-05 & $-5.63 E-05 * * *$ & 1.78E-05 \\
\hline Unemployment rate & 0.017 & 0.018 & 0.011 & 0.015 \\
\hline Year & $-0.057^{* * *}$ & 0.017 & $-0.063^{* * *}$ & 0.018 \\
\hline Crime per officer & & & $0.328 * * *$ & 0.127 \\
\hline Drug arrests/total crime & & & 2.722 *** & 0.656 \\
\hline Constant & $122.440 * * *$ & 35.204 & $118.105^{* * *}$ & 37.157 \\
\hline
\end{tabular}

All models include as additional regressors city fixed effects.

${ }^{* * *}$ Indicates significance at $1 \%$ level (two-tailed test), ${ }^{* *}$ indicates significance at $5 \%$ level (two-tailed test) and * indicates significance at the 10\% level (two-tailed test). 
Table 7

GLM Estimates of Log Crime Rates from UCR: 1994 -1999

\begin{tabular}{|c|c|c|c|c|}
\hline & \multicolumn{2}{|l|}{ M1 } & \multicolumn{2}{|l|}{ M2 } \\
\hline & $\begin{array}{c}\text { OLS } \\
\text { Coefficient }\end{array}$ & $\begin{array}{l}\text { Robust } \\
\text { Std. Err }\end{array}$ & $\begin{array}{c}\text { OLS } \\
\text { Coefficient }\end{array}$ & $\begin{array}{l}\text { Robust } \\
\text { Std. Err }\end{array}$ \\
\hline & \multicolumn{4}{|c|}{ Log (\# of violent crimes/10K pop) } \\
\hline Real price of $\mathrm{MJ}$ & -0.009 & 0.006 & -0.005 & 0.003 \\
\hline Real price of Cocaine & 0.004 & 0.003 & 0.000 & 0.003 \\
\hline Real beer tax & $0.286 * * *$ & 0.069 & $0.172 * *$ & 0.070 \\
\hline $\log ($ county pop) & $-1.123 * *$ & 0.497 & $-1.831^{* * *}$ & 0.443 \\
\hline$\%$ of county pop < 18 & $7.929 * *$ & 3.796 & 4.942 & 3.190 \\
\hline$\%$ of county pop black & 4.621 & 3.537 & $12.023 * * *$ & 2.995 \\
\hline$\%$ of county pop other race & 20.524 * & 12.237 & 9.770 & 8.906 \\
\hline$\%$ of county pop Hispanic & -3.279 & 6.029 & 2.631 & 3.432 \\
\hline Real per capita income & $-2.72 \mathrm{E}-02 * * *$ & 1.03E-02 & $-2.00 \mathrm{E}-02$ * & 1.14E-02 \\
\hline Unemployment rate & 0.013 & 0.016 & 0.008 & 0.016 \\
\hline Year & $-0.047^{* * *}$ & 0.013 & $-0.054 * * *$ & 0.015 \\
\hline Crime per officer & & & $0.518^{* * *}$ & 0.101 \\
\hline Drug arrests/total crime & & & $-0.578 *$ & 0.326 \\
\hline \multirow[t]{2}{*}{ Constant } & $108.014^{* * *}$ & 30.087 & $129.284^{* * *}$ & 34.111 \\
\hline & \multicolumn{4}{|c|}{ Log (\# of property crimes / $10 \mathrm{~K}$ pop) } \\
\hline Real price of MJ & -0.003 & 0.003 & $-0.005^{*}$ & 0.003 \\
\hline Real price of Cocaine & 0.003 & 0.002 & 0.003 & 0.002 \\
\hline Real beer tax & $0.186^{* * *}$ & 0.045 & 0.026 & 0.053 \\
\hline $\log ($ county pop) & $0.718 *$ & 0.418 & 0.057 & 0.299 \\
\hline$\%$ of county pop < 18 & 0.092 & 3.026 & $9.524 * * *$ & 2.537 \\
\hline$\%$ of county pop black & 0.151 & 3.146 & -2.015 & 2.840 \\
\hline$\%$ of county pop other race & -6.555 & 5.029 & -5.729 & 3.816 \\
\hline$\%$ of county pop Hispanic & $-6.965 * *$ & 3.139 & $-9.127^{* * *}$ & 2.355 \\
\hline Real per capita income & $-1.44 \mathrm{E}-02$ ** & 7.16E-03 & 4.33E-03 & 7.54E-03 \\
\hline Unemployment rate & 0.013 & 0.013 & 0.006 & 0.009 \\
\hline Year & 0.002 & 0.015 & $0.026 * *$ & 0.013 \\
\hline Crime per officer & & & $0.467^{* * *}$ & 0.064 \\
\hline Drug arrests/total crime & & & $-1.704^{* * *}$ & 0.324 \\
\hline Constant & -8.122 & 30.964 & -48.733 & 26.608 \\
\hline
\end{tabular}

All models include as additional regressors city fixed effects.

${ }^{* * *}$ Indicates significance at $1 \%$ level (two-tailed test), ${ }^{* *}$ indicates significance at $5 \%$ level (two-tailed test) and * indicates significance at the 10\% level (two-tailed test). 


\section{APPENDIX}

Table A1. Marginal Effects and Robust Standard Errors from Probit Estimation of Prob(Using Marijuana) ${ }^{\mathrm{a}}$

\begin{tabular}{|c|c|c|c|c|c|c|}
\hline & MJ50 & & MJ72HR & & UNDERMJ & \\
\hline \multirow{2}{*}{ Price MJ } & -0.0011 & * & -0.0011 & * & -0.0006 & $\overline{* \star}$ \\
\hline & $(0.001)$ & & $(0.001)$ & & $(0.000)$ & \\
\hline \multirow{2}{*}{ MALE } & 0.1491 & $\star \star \star \star *$ & 0.0863 & 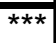 & 0.0266 & $\star * * *$ \\
\hline & $(0.003)$ & & $(0.003)$ & & $(0.001)$ & \\
\hline \multirow{2}{*}{ BLACK } & 0.0294 & $\star \star \star *$ & 0.0439 & $\overline{\star \star \star \star}$ & 0.0059 & $\star * * *$ \\
\hline & $(0.004)$ & & $(0.004)$ & & $(0.002)$ & \\
\hline \multirow{2}{*}{ HISPANIC } & -0.0722 & *** & -0.0592 & $\overline{\star \star \star \star}$ & -0.0114 & 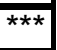 \\
\hline & $(0.005)$ & & $(0.004)$ & & $(0.002)$ & \\
\hline \multirow{2}{*}{ OTHR RACE } & -0.1022 & *** & -0.0676 & $\pi * \star$ & -0.0108 & $\overline{* * *}$ \\
\hline & $(0.009)$ & & $(0.008)$ & & $(0.004)$ & \\
\hline \multirow{2}{*}{ AGED 18-24 } & 0.0375 & $\overline{\star \star \star \star ~}$ & 0.0280 & $\overline{* * *}$ & -0.0009 & \\
\hline & $(0.005)$ & & $(0.005)$ & & $(0.002)$ & \\
\hline \multirow{2}{*}{ AGED 25-34 } & -0.1381 & $* * *$ & -0.0699 & $\overline{* \star \star}$ & -0.0279 & 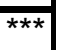 \\
\hline & $(0.005)$ & & $(0.005)$ & & $(0.002)$ & \\
\hline \multirow{2}{*}{ AGED $>34$} & -0.2601 & $\overline{* \star \star}$ & -0.1728 & $\overline{* \star *}$ & -0.0566 & *** \\
\hline & $(0.004)$ & & $(0.004)$ & & $(0.002)$ & \\
\hline \multirow{2}{*}{ EDU12 } & -0.0584 & 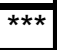 & -0.0569 & $\overline{* \star *}$ & -0.0138 & 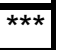 \\
\hline & $(0.003)$ & & $(0.003)$ & & $(0.001)$ & \\
\hline \multirow{2}{*}{ MEDUC } & 0.0133 & ** & 0.0196 & 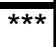 & 0.0033 & \\
\hline & $(0.006)$ & & $(0.006)$ & & $(0.002)$ & \\
\hline \multirow{2}{*}{$\begin{array}{l}\text { LEGAL } \\
\text { INCOME }\end{array}$} & 0.0000 & $\overline{* \star \star}$ & 0.0000 & $\overline{* \star \star}$ & 0.0000 & $\overline{* * \star}$ \\
\hline & $(0.000)$ & & $(0.000)$ & & $(0.000)$ & \\
\hline \multirow{2}{*}{$\begin{array}{l}\text { ILLEGAL } \\
\text { INCOME }\end{array}$} & 0.0000 & 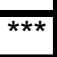 & 0.0000 & 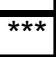 & 0.0000 & 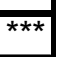 \\
\hline & $(0.000)$ & & $(0.000)$ & & $(0.000)$ & \\
\hline \multirow{2}{*}{ YEAR } & 0.0051 & ** & 0.0054 & ** & 0.0032 & 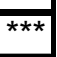 \\
\hline & $(0.002)$ & & $(0.002)$ & & $(0.001)$ & \\
\hline \multirow{2}{*}{$\begin{array}{l}\text { PRICE } \\
\text { BEER }\end{array}$} & 0.0038 & & 0.0339 & $\star \star \star$ & 0.0007 & \\
\hline & $(0.016)$ & & $(0.015)$ & & $(0.007)$ & \\
\hline \multirow{2}{*}{$\begin{array}{l}\text { Distance } \\
\text { Indicator }\end{array}$} & 0.0418 & 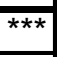 & 0.0119 & * & -0.0054 & \\
\hline & $(0.007)$ & & $(0.007)$ & & $(0.003)$ & \\
\hline \multirow{2}{*}{$\begin{array}{c}\text { PRICE } \\
\text { COCAINE }\end{array}$} & 0.0004 & & 0.0006 & & 0.0000 & \\
\hline & $(0.001)$ & & $(0.001)$ & & $(0.000)$ & \\
\hline \multirow{2}{*}{ QUARTER } & -0.0021 & & -0.0016 & & 0.0005 & \\
\hline & $(0.001)$ & & $(0.001)$ & & $(0.001)$ & \\
\hline
\end{tabular}

Statistical significance is designated as follows: ${ }^{* * *}$ indicates significance at the $1 \%$ level (2-tailed test), ${ }^{* *}$ indicates significance at the $5 \%$ level, and * indicates significance at the $10 \%$ level. 
Table A2.

ADAM Locations and Fipscodes

\begin{tabular}{|l|c|l|c|}
\hline Albuquerque & 35001 & Minneapolis & 27053 \\
\hline Anchorage & 2020 & New Orleans & 22071 \\
\hline Atlanta & 13121 & New York & 36061 \\
\hline Birmingham & 1073 & Oklahoma City & 40109 \\
\hline Chicago & 17031 & Omaha & 31055 \\
\hline Cleveland & 39035 & Philadelphia & 42101 \\
\hline Dallas & 48113 & Phoenix & 4013 \\
\hline Denver & 8031 & Portland & 41051 \\
\hline Des Moines & 19153 & Sacramento & 6067 \\
\hline Detroit & 26163 & Salt Lake City & 49035 \\
\hline Ft. Lauderdale & 12011 & San Antonio & 48029 \\
\hline Houston & 48201 & San Diego & 6073 \\
\hline Indianapolis & 18097 & San Jose & 6085 \\
\hline Kansas City & 29095 & Seattle & 53033 \\
\hline Laredo & 48479 & Spokane & 53063 \\
\hline Las Vegas & 32003 & St. Louis & 29189 \\
\hline Los Angeles & 6037 & Tucson & 4019 \\
\hline Miami & 12086 & Washington & 11001 \\
\hline
\end{tabular}

NOTE: Sites included in the county analysis are those listed in Table 1 except Kansas City, which did not report any data for 1995-1999. Quarterly data is averaged (annually) for the county-level analysis.

From the ADAM codebooks: "Prior to 1998, samples of arrestees for the ADAM/DUF program were drawn from booking facilities within each of the sites and thus were limited to the types of arrestees booked at these facilities. In 11 sites (Atlanta, Chicago, Cleveland, Denver, Detroit, Houston, Kansas City, Omaha, Philadelphia, St. Louis, and Washington, DC), the catchment area represented the central city. The data from the city of Denver included Denver County in its entirety, and the St. Louis data also encompassed a county. (Kansas City ceased being a DUF site after 1992.) In ten additional sites (Dallas, Ft. Lauderdale, Indianapolis, Miami, New Orleans, Manhattan [New York City], Phoenix, Portland, San Antonio, and San Jose), the catchment area was the county, parish, or borough." Post-1997, ADAM expanded as well as "enhanced each site's collection to include the entire county" (NIJ, 2000b). 